\title{
DIFICULDADES, DESAFIOS E POSSIBILIDADES PARA UMA CLÍNICA SARTREANA
}

\author{
Difficulties, Challenges and Possibilities for a Sartrean Clinic \\ Dificultades, Retos y Posibilidades para una Clínica Sartreana
}

FERNANDA Alt

Carolina Mendes Campos

ANDRÉ BARATA

\begin{abstract}
Resumo: Refletir sobre a possibilidade de uma clínica fenomenológico-existencial é ainda hoje um grande desafio para os profissionais e estudiosos deste campo. Por se tratar de um trabalho que parte da filosofia, este se revela por vezes mais árduo, ao se mostrar carente de pressupostos psicológicos. No entanto, esta carência, longe de ser um impedimento, abre espaço para pensarmos em uma clínica desembaraçada das amarras cientificistas e positivistas que impregnaram a psicologia desde o seu nascimento. Frente a essa possibilidade, destacamos dentre as filosofias fenomenológicas e existenciais a de Jean-Paul Sartre, devido à constante preocupação presente em sua extensa obra de considerar criticamente as teorias psicológicas. É diante deste panorama que pretendemos, neste artigo, levantar algumas considerações sobre o desafio de pensar e realizar uma psicologia fenomenológico-existencial, tendo em vista a importância de sustentar o caráter crítico do qual ela é oriunda. Para tal, discutimos o problema da "importação" de conceitos por via de noções fundamentais do pensamento de Sartre, como liberdade e má-fé.

Palavras-chave: Fenomenologia; Existencialismo; Psicologia clínica; Liberdade; Má-fé.
\end{abstract}

Abstract: Reflecting on the possibility of a phenomenological-existential clinical is still a great challenge for professionals and scholars of such field. Because it is a work that stems from philosophy, it sometimes proves to be more difficult, as it shows to have a lack of psychological assumptions. However, this gap, far from being an impediment, opens our minds up for thinking about a clinical cleared of its scientistic and positivist ties that have permeated psychology since its birth. Faced with this possibility, we highlight among the existential and phenomenological philosophies the one of Jean-Paul Sartre, owing to his constant concern during his extensive work to critically consider psychological theories. It is before this scenario that we intend in this article to raise some considerations about the challenge of thinking and realizing an existential-phenomenological psychology keeping in mind, at the same time, the importance of preserving the critical character of which it is originated. To this end, we discussed the problem of the "importation" of concepts by considering some fundamental notions of Sartre's thought, like freedom and bad faith.

Keywords: Phenomenology; Existentialism; Clinical psychology; Freedom; Bad faith.

Resumen: Reflexionar sobre la posibilidad de una clínica fenomenológica-existencial es todavía un gran desafío para los profesionales y estudiosos en este campo. Teniendo en cuenta que este es un trabajo que parte de la filosofía, esto a veces resulta ser más difícil, por mostrar la carencia de los presupuestos psicológicos. Sin embargo, esta carencia, lejos de ser un impedimento, deja un espacio abierto para pensarnos en una clínica libre de las amarras del cientificismo y del positivismo que ha impregnado la psicología desde su nacimiento. Ante esta posibilidad, destacamos entre las filosofías existenciales y fenomenológicos a de Jean-Paul Sartre, debido a la constante preocupación presente en su extensa obra de considerar críticamente las teorías psicológicas. Es en este contexto que pretendemos en este artículo plantear algunas consideraciones sobre el desafío de pensar y realizar una psicología existencial-fenomenológica teniendo en cuenta la importancia de sustentar el carácter crítico de lo cual proviene. Con este fin, hemos discutido el problema de la "importación" de conceptos a través de las nociones fundamentales del pensamiento de Sartre, como la libertad, y la mala fe.

Palabras Clave: Fenomenología; Existencialismo; Psicología clínica; Libertad; Mala fe.

\section{Introdução}

Considerar as possibilidades de uma clínica fenomenológico-existencial continua, hoje, a ser um desafio para os profissionais e estudiosos no campo da psicologia clínica. A princípio, esse desafio parece se anunciar pelo fato de estarmos nos referindo a uma zona de entrecru- zamentos metodológicos, práticos e conceituais, seja na referência a uma metodologia fenomenológica, já por si mesma plural, seja na inspiração numa atitude existencial que nem sempre, porém, é entendida no sentido de um existencialismo, seja, enfim, na origem destas perspectivas não no campo da psicologia clínica, mas no da filosofia. Tal entrecruzamento nos confronta com os ris- 
cos e dificuldades que sempre resultam do diálogo interdisciplinar, das suas articulações e apropriações, com migrações conceituais não raras vezes equívocas, bem como da árdua tarefa de fazer a ponte entre o plano da teoria psicológica e o da prática clínica.

Aliás, a problemática não segue apenas na direção de entrada para o campo da psicologia clínica. Já dentro deste campo, têm sido tantas as abordagens, cambiando aspectos, inspirações e filiações, que se torna difícil o mapeamento exato das suas diferenças e, talvez mais importante, das suas expectativas face ao que o pensamento fenomenológico e existencial pode trazer à prática clínica na psicologia. Apesar da ingenuidade de algumas formulações adotadas pelos psicólogos americanos que, há mais de meio século, avançaram com a perspectiva de uma psicologia e de uma psicoterapia existenciais, Rollo May (1960) já advertia sabiamente que era "duvidoso que tenha sentido falar-se de um 'psicólogo ou psicoterapeuta existencial', em contraposição a outras escolas" (p. 17). E explicitava em seguida o seu pensamento nos seguintes termos:

Existencialismo não é um sistema de terapia, mas uma atitude para com a terapia. Muito embora tenha conduzido a muitos avanços na técnica, não é um conjunto de técnicas por si mesmas, mas é um interesse pela compreensão da estrutura do ser humano e sua experiência que deve sustentar todas as técnicas (May, 1960, p. 17-18).

Esta exigência de "compreensão da estrutura do ser humano e sua experiência”, no quadro de uma "atitude" existencial face à terapia não autoriza a sua dogmatização num receituário de técnicas. Fazer prevalecer a atenção crítica sobre os esquematismos generalizadores e abstratos e sobre os determinismos é um dos aspectos mais notáveis nas reflexões que Jean-Paul Sartre produziu quer sobre a psicologia, quer sobre a psicanálise.

O presente artigo anima-se deste propósito tão sartriano de atenção crítica, mas precisamente tomando como objeto algumas das noções mais celebrizadas (e também por isso muitas vezes simplificadas) que o existencialista cunhou ao longo da sua reflexão. Em concreto, propomos discutir, com este artigo, a "importação" de noções sartreanas como as de liberdade e má-fé para o âmbito da clínica fenomenológico-existencial.

No itinerário da obra de Sartre encontramos reflexões marcantes, a partir de uma abordagem fenomenológica, para uma psicologia da imaginação e das emoções, bem como de uma descrição das estruturas psíquicas dos estados e qualidades do Ego. Além das importantes contribuições para uma psicologia fenomenológica, no sentido que Edmund Husserl atribuía a esta nova disciplina, Sartre também sustenta uma longa interlocução com Sigmund Freud, indicação de uma ambição sua de ir além de especulações teóricas e desenvolver um esboço me- todológico que pudesse servir de base para uma prática clínica. Apesar de discordar de alguns dos pressupostos fundamentais da psicanálise freudiana como, por exemplo, a postulação da hipótese do inconsciente, esta forma de abordagem das questões relativas ao homem é a principal inspiração para o projeto levado a cabo por Sartre de uma psicanálise existencial. Tal projeto o ocupará ao longo de sua obra de forma recorrente e significativa, desde $O$ ser e o nada até $O$ idiota da família, aliando às suas críticas metapsicológicas à psicanálise empírica uma permanente preocupação metodológica, em particular no que diz respeito à fundamentação de um método de compreensão do homem.

O fato de podermos identificar no rastro da obra de Sartre um "caminho a seguir" em vista de uma clínica psicológica de recorte sartriano, dentro do círculo das abordagens fenomenológico-existenciais, não suprime as dificuldades teóricas e metodológicas a serem enfrentadas. No intuito de trilhar esse caminho de Sartre devemos, de início, voltar brevemente nossa atenção para sua crítica a uma psicologia que ainda carregava a marca do espírito de seu tempo: legitimar-se como ciência empírica, ao lado de outras ciências empíricas como a física e a química, alicerçadas na ideia de um método científico natural. Para que a psicologia pudesse alcançar semelhante status, era necessário desenvolver um método particular cientificamente equivalente, valendo-se das mesmas ideias positivistas das ciências da natureza. Deste modo, a psicologia tomou de "empréstimo" de outras disciplinas já legitimadas um molde previamente elaborado, no qual deveria se encaixar com o máximo de exatidão. Os problemas subseqüentes deste “empréstimo", feito pelas ciências humanas em geral, foram muito bem explorados por pensadores como Wilhelm Dilthey e Edmund Husserl, ao afirmarem a necessidade de demarcar as ciências compreensivas, nelas incluindo-se a psicologia e todas as disciplinas visando à compreensão do humano, das ciências naturais e da sua epistemologia baseada no princípio da explicação causal.

Prosseguindo esta linha de demarcação, Sartre, por sua vez, imprime o seu cunho crítico aos problemas de fundamentação epistemológica da psicologia. Sua intenção, aliás, vai além da mera crítica epistemológica ao modelo naturalista positivista ao oferecer pressupostos da fenomenologia de Husserl como alternativa para uma psicologia, conforme podemos observar em Esboço para uma teoria das emoções ou em A transcendência do ego. No Esboço, Sartre (2007) demonstra que o problema da psicologia está em estabelecer suas premissas a partir dos fatos isolados, o que significa que ela busca "encontrar" na experiência dos fatos o seu objeto sem definir anteriormente o que seria este objeto. Sabemos que este "objeto" pesquisado pela psicologia é o homem, e esta falta de definição anterior acaba, segundo Sartre (2007), por transformar a idéia de homem em uma abstração, em um conceito vazio. Para os psicólogos, tal definição aparece 
como resultado dos fatos pesquisados que, agrupados e classificados, oferecem empiricamente suas características. Assim, a psicologia parte, de acordo com o filósofo, de uma pretensa posição "neutra” diante de seu objeto de estudo, como se o pesquisador pudesse encontrar o "homem" ao final da investigação e não o colocasse em questão desde o início, esquecendo-se de que ele mesmo pertence à realidade que estuda: "eles (psicólogos) querem estar diante de seu objeto como o físico diante do dele" (Sartre, 2007, p. 13). Por conseqüência, o psicólogo acaba por retirar de sua investigação aquilo que mais interessa ao fenomenólogo: a significação.

Para a fenomenologia, "todo fato humano é por excelência significativo” (Sartre, 2007, p. 25), e por esta razão o ponto de partida deverá ser um estudo dos fenômenos e não dos fatos empíricos positivos, isto é, partir da relação da consciência intencional com o mundo. No caso da emoção, por exemplo - estudada pelo psicólogo como fato psíquico -, a psicologia fenomenológica deverá fazer uma dupla interrogação ao fenômeno:

Assim, o fenomenólogo interrogará a emoção sobre a consciência ou sobre o homem, perguntar-lhe-á não apenas o que ela é, mas o que tem a nos ensinar sobre um ser do qual uma das características é justamente ser capaz de se emocionar. E, inversamente, interrogará a consciência, a realidade humana sobre a emoção: o que deve ser então uma consciência para que a emoção seja possível, talvez até para que seja necessária? (Sartre, 2007, p. 25).

Trata-se de uma questão de ponto de partida, de uma atitude inicial. A psicologia positivista parte do pressuposto de que o mundo de alguma forma está dado e que o esforço consiste em estudar com rigor os fatos empíricos positivos para que deles brotem as verdades. Como diz Sartre (2007), esta psicologia positivista estuda o homem da mesma forma que o botânico analisa e classifica as plantas, procurando enquadrar o humano em categorias taxonômicas e leis naturais. Em contrapartida, a atitude fenomenológica, ao buscar as significações, convida a psicologia a "dar um passo atrás" e interrogar, a relação do homem com o mundo.

Posto isto, é importante evitar quatro confusões recorrentes acerca do estatuto que Sartre se propõe conferir à psicologia fenomenológica, mas desde logo clarificadas nas primeiras páginas de A Transcendência do Ego. Em primeiro lugar, tal psicologia fenomenológica apresenta-se como uma disciplina científica, dotada da mesma ambição de rigor e objetividade que quaisquer outras ciências apregoem para si - longe de se tratar de uma psicologia anti-científica ou contra o discurso científico, a aposta da psicologia fenomenológica consiste em pensar a ciência de uma maneira diferente da do cientificismo e do positivismo redutor. Em segundo lugar, o fato de Sartre começar por um exame crítico das bases epistemológi- cas da psicologia do seu tempo, aliás muito inspirado no movimento de Husserl, não converte a sua psicologia numa psicologia crítica no sentido em que se contentasse com o exame das suas condições de possibilidade, à maneira de um tribunal da razão kantiano. Em terceiro lugar, e na sequência do ponto anterior, importa deixar claro que a psicologia fenomenológica, e a fenomenologia em geral, não são ciências apriorísticas que constituem o seu conhecimento independentemente da experiência. Bem pelo contrário, é lema central da fenomenologia o retorno às coisas mesmas, às coisas na sua concreta aparição, imersas na sua significação integral. Por último, e concluindo estas sequências de observações, a psicologia fenomenológica é uma ciência de fatos. Evidentemente, não uma ciência de fatos empíricos positivos, dados no seu recíproco isolamento e explicados através de uma lógica causal conferida externamente, a partir da constatação e generalização de correlações, mas uma ciência de fatos relativos à consciência, fatos dotados de significação a esclarecer fenomenologicamente, tal qual se dão à consciência, seu fato primeiro e absoluto.

A fenomenologia é um estudo científico e não crítico da consciência. $\mathrm{O}$ seu procedimento essencial é a intuição. A intuição, segundo Husserl, põe-nos na presença da coisa. Deve entender-se que a fenomenologia é, portanto, uma ciência de fato e que os problemas que ela põe são problemas de fato, como aliás se pode ainda perceber considerando que Husserl a denomina uma ciência descritiva. Os problemas das relações do Eu com a consciência são, portanto, problemas existenciais. (...) Esta consciência já não é um conjunto de condições lógicas, é um fato absoluto (Sartre, 1994, p. 45).

Estas são as bases constituintes da psicologia fenomenológica que Sartre propõe nos seus primeiros ensaios e que servem de apoio para o desdobramento de seu pensamento existencial como um todo, cujas idéias principais são: 1) a radicalização do princípio de intencionalidade - retirando à consciência qualquer possibilidade de ser mais do que o movimento de fuga em direção às coisas; 2) a assunção do ser da consciência como liberdade - retirando-lhe a possibilidade de ser determinada por algo mais além dela mesma; 3) a descrição da estrutura meta-estável da consciência - como ser que é o que não é e não é o que é; 4) a descrição da angústia como apreensão reflexiva da própria condição livre e indeterminável da consciência, 5) a má-fé como uma conduta de fuga à angústia, procurando o descanso de um determinismo, seja o das condições sociais, seja o de um inconsciente e suas pulsões, seja o de qualquer outro expediente que vise alijar as responsabilidades pelas próprias escolhas. Assim, se vai costurando aquilo que com inteira legitimidade se pode designar por psicologia fenomenológicoexistencial sartreana, nela podendo incluir-se as bases 
para o projeto que Sartre inicia em O Ser e o nada de uma psicanálise existencial, bem como das suas perspectivas sobre as relações concretas com o outro.

Contudo, aquela vontade de fazer ciência que animou, na esteira de Husserl, a psicologia fenomenológica nas obras iniciais de Sartre, não pode ser sobrestimada no quadro do pensamento do existencialista. Pelo contrário, é crucial compreender em que medida tal ambição "científica" deve ser situada e subordinada, ainda que não superada, se se quiser tomar, em todo o seu alcance, as consequências do pensamento de Sartre para uma clínica psicológica. Com efeito, a postura científica, elaborada de dentro de uma disciplina científica, esgota-se diante da necessidade de remontar do plano do $\mathrm{Co}$ nhecer, de algum modo sempre já derivado, ao plano das relações de ser. No essencial, é essa a crítica que Sartre dirige a Husserl. De outro modo, algo fundamental para uma clínica psicológica como a compreensão das relações concretas entre os homens veria as suas possibilidades anular-se. Além disso, o projeto de uma psicanálise sartreana, justamente porque existencial, perderia a sua maior originalidade se se deixasse enredar na ideia de uma psicanálise científica. Não está em causa, com isto, tornar impertinente a questão de um método, mas a sua configuração como um método pensado através de requisitos científicos de aplicabilidade repetida, previsibilidade, fiabilidade, etc. O movimento que leva Sartre de uma psicologia fenomenológica à afirmação de uma ontologia fenomenológica não pode, portanto, ser entendido simplesmente como continuação de um fazer científico num campo disciplinar delimitado através da definição de um objeto de estudo e aplicação de uma metodologia para o investigar.

Evidentemente, da investigação ontológica sartreana resulta um "saber" que caracterizará a clínica fenomenológico-existencial e que moldará escolhas no relacionamento terapêutico. Por exemplo, que nenhum a priori, nenhuma abstração, deve interpor-se na compreensão das relações inter-pessoais. Tal como a existência precede a essência, também a ontologia da relação precede qualquer ciência da relação. Tal "saber" que precede a "ciência” deverá incorporar, e assim caracterizar distintivamente, uma clínica fenomenológico-existencial que se reclame sartreana.

\section{O Problema da "Importação" de Conceitos Filosóficos na Psicologia}

De acordo com Ana Maria Feijoo (2009), não são poucas as indagações em torno do que seria uma psicologia fenomenológico-existencial, especialmente quando se trata de pensar uma prática clínica. Em meio a mal-entendidos e confusões entre correntes de pensamentos, também não são poucas as dificuldades a serem transpostas. Dentre os percalços inerentes a este caminho,
Feijoo (2009) ressalta a constante e complicada tentativa de junção, na psicologia, das filosofias da existência ao pensamento humanista. No caso de Sartre, pensamos que essa mistura é acentuada pelo próprio autor que dá o nome de "O Existencialismo é um Humanismo" a uma de suas conferências que viria a se tornar um de seus textos mais lidos. Em tal conferência, ele explica que o termo "humanismo" se aplica em dois sentidos distintos. O primeiro sentido "toma o homem como meta e como valor superior" (Sartre, 1987, p. 21), o que acaba por gerar um tipo de culto da "humanidade", na qual ela é vista como admirável e louvável, conduzindo a uma visão viciada de homem e a um humanismo solipsista. Esta concepção não se assemelha a do existencialismo sartriano, já que nela o homem nunca é tomado como meta, como um modelo vangloriável, que é pronto e fechado em si, "pois ele (homem) está sempre por se fazer” (Sartre, 1987, p. 21). Se o homem está "por se fazer", ele é busca por metas fora de si, em um movimento incessante que expressa sua indissociável relação com o mundo. O sentido de "humanismo" que Sartre sustenta remete assim a paradoxal condição da existência, na qual o homem só se faz homem perdendo-se fora de si.

Talvez Sartre tenha sentido a urgência de privilegiar o "humano" em toda a sua concretude no bojo do pensamento fenomenológico-existencial, por considerar que seus precursores deram ou excessiva importância à questão do conhecimento ou um "passo a mais" na crítica ao subjetivismo, deixando assim o olhar relativo ao homem ora embaçado pela poeira racional da teoria, ora perdido em relação à experiência mais concreta e cotidiana. Neste sentido, o esforço de Sartre é o de recuperar este "homem-no-mundo" entendido, por sua vez, como radicalmente distinto do homem exultado no centro do pensamento humanista.

Na psicologia, esta distinção entre os "humanismos" se torna essencial, visto que o humanismo clássico se encontra na base de uma teoria psicológica que enveredou para o desenvolvimento de uma prática que permanece ligada a pressupostos de ordem da natureza humana, afastando-se da formulação básica das teorias existenciais, na qual "a existência precede a essência”. Apesar de tal diferença de pressupostos, muitas leituras se formaram na tentativa de manter essa conexão entre o existencialismo e o humanismo. Isso se faz notar na própria denominação corrente de "Psicologia Humanista Existencial", muito em voga principalmente a partir da segunda metade do século XX. A abordagem "Humanista Existencial" surge como uma tentativa de transpor noções da filosofia fenomenológica e existencial aos princípios da Psicologia clínica, fato que pode ser observado, por exemplo, em algumas leituras entusiasmadas, mas igualmente precipitadas, do pensamento de Sartre por parte de psicólogos humanistas norte-americanos. Esse movimento suscita, até hoje, dúvidas quanto aos problemas das "importações" dos conceitos filosóficos, visto que nesta proposta 
é inevitável pôr a serviço da psicologia centrada numa essência de pessoa humana um pensamento que visa justamente desconstruí-la. Em outras palavras, a abordagem "Humanista Existencial" se utiliza de noções como angústia, desamparo, desespero e liberdade de modo a diluí-las em um escopo teórico mais amplo, no qual estas são acrescidas de ideias chaves da psicologia clássica como as de saúde/doença, cura, processo terapêutico e, sobretudo, ideias humanistas de difícil compatibilidade com o pensamento fenomenológico-existencial como as de pessoa interior, potencialidade e atualização, crescimento interior e natureza humana.

Por estas razões, é certo que o humanismo implicado na terapia centrada na pessoa de Carl Rogers, referência maior da psicologia humanista, só enganadoramente pode encontrar fundamento filosófico, caso dele carecesse, no pensamento existencial de Sartre, ou mesmo, num sentido mais amplo, no pensamento fenomenológico tout court - "Uma psicoterapia centrada na pessoa é incompatível com uma psicoterapia fenomenológica” (Moreira, 2009, p. 36). Isto não significa, porém, que sejam improcedentes todas e quaisquer aproximações entre humanismo e fenomenologia, ou ainda, entre humanismo e existencialismo. São, a este propósito, dignas de nota as leituras do próprio trabalho rogeriano que testemunham uma mudança de perspectiva em sua prática clínica, já não tendo a "pessoa como centro", mas visando "para além da pessoa", designadamente a "relação cliente-terapeuta" e de "campo em comum” (Moreira, 2009, p. 35-36).

A tentativa de evitar uma simples "importação" de termos filosóficos, mantendo ao mesmo tempo as possibilidades abertas para uma prática clínica parece traduzirse no desafio da psicologia fenomenológico-existencial ainda hoje. Se seguirmos o caminho de Sartre, surpreendentemente ainda tão pouco explorado, podemos compreender que para que essa clínica seja possível é preciso, primeiramente, dar "um passo atrás" e reencontrar o solo ontológico donde se constitui fenomenologicamente uma psicologia. Isto implica em desimpregná-la de suas bases cientificistas e normativas e tomar o homem não mais pela perspectiva de uma subjetividade solipsista, abstração de si mesmo, mas pela prerrogativa primeira da fenomenologia que aponta para uma relação indissociável entre o homem-e-seu-mundo.

A possibilidade de articulação de uma prática clínica a partir de Sartre deve, portanto, levar em consideração este esforço de pensar mais originariamente, ou seja, na atenta consideração das fontes fenomenológicas de investigação psicológica. Pautados nesta atitude, podemos tomar as noções desenvolvidas por Sartre em torno da psicologia como um projeto que ultrapassa sua própria postulação metodológica de psicanálise existencial. Camila Gonçalves (2006) ressalta que a psicanálise sartreana deve também abarcar toda a análise ontológica presente em O Ser e o Nada, que envolve descrições acerca "da contingência, da facticidade, do ser do valor, do ser dos possíveis, do eu, da temporalidade, e da ipseidade" (p. 58). Desta forma, devido ao amplo desafio de produzir uma prática na zona de encontros (ou desencontros) entre a psicologia e a filosofia, devemos caminhar de modo a evitar uma busca "apressada” por definições provenientes da ontologia que seriam "importadas" e "diluídas" em um escopo psicologizante transformando-as em normatizações.

Tal risco se evidencia, a nosso ver, principalmente em relação às noções sartreanas de liberdade e má-fé que, por se apresentarem como os jargões de base de um pensamento amplamente difundido, acabam por ser interpretadas de forma confusa. Na psicologia, isso se expressa em uma leitura que faz equivaler liberdade e vontade, e de acordo com a qual a psicoterapia passa a servir como um espaço de reflexão que visa promover uma atitude voluntariamente responsável sobre as livres escolhas. Ora, em tal interpretação a existência se reduz àquilo que "quero (reflexivamente) ser"; as escolhas são encaradas como enganosas ou autênticas no intuito de direcionarem as mudanças a serem tomadas responsavelmente pelo sujeito. Esta é, contudo, uma interpretação que se afasta consideravelmente do espírito e da letra do pensamento de Sartre.

Com efeito, a liberdade sartreana em nada se equivale à vontade, pelo contrário; segundo ele, a vontade não é senão uma anunciadora do que a liberdade já escolheu: "Quando delibero, os dados já estão lançados (...) Quando a vontade intervém, a decisão já está tomada, e a vontade não tem outro valor senão o de anunciadora" (Sartre, 2001, p. 557). Escolhemos simplesmente porque somos liberdade, esta é uma condição ontológica de nosso ser, que significa a nossa não determinação por uma natureza substancial. Tal condição de não-natureza determinante indica, por si só, que cada traço do existir é uma escolha, ou, nas palavras de Sartre:

O homem é livre porque não é si mesmo, mas presença a si. O ser que é o que é não poderia ser livre. A liberdade é precisamente o nada que é tendo sido no âmago do homem e obriga a realidade-humana a fazer-se em vez de ser (...) para a realidade-humana ser é escolher-se (Sartre, 2001, p. 545, grifo do autor).

Logo, devemos pensar mais originariamente, a saber, devemos "pensar contra" a tendência natural de atribuirmos um caráter reflexivo à escolha, a qual nos joga rapidamente na interpretação de uma liberdade voluntarista que "escolhe o que quer ser". Para Sartre (2001), o ideal da vontade é um ideal reflexivo que nos conduz ao "sentido da satisfação que acompanha um juízo como 'fiz o que quis”” (p. 558). A escolha fundamental da liberdade sartreana é anterior a reflexão, é irrefletida e espontânea, constitutiva dos próprios caminhos da reflexão. Isto indica uma principialidade e autonomia do irrefletido em Sartre, como destaca Pedro Alves (1994), posto que "no 
seio da vivência irrefletida, se consuma já um saber atemático de si que é independente e autônomo relativamente à consciência reflexiva” (p. 11). Em outras palavras, esse saber atemático da vida irrefletida se dá pelo que Sartre denominou de cogito pré-reflexivo, uma relação primeira da consciência consigo mesma, que se escolhe anteriormente e independentemente de qualquer reflexão. Escolhas irrefletidas e espontâneas não representam, assim, uma eleição de si alienada e irresponsável, mas apenas um movimento original. A responsabilidade existencial em Sartre se aproxima a noção de cuidado (sorge) de Heidegger, na qual mesmo o descuido é compreendido como uma forma de ser cuidado. Isso também vale para a responsabilidade sartreana, já que mesmo decidindo sobre mim de forma irrefletida ainda assim sou responsável pelo que escolho, não havendo necessidade de um recurso de segundo grau (reflexão), para que a responsabilidade entre em jogo.

Dentro desta mesma perspectiva podemos considerar que também a noção de má-fé corre o risco de ser interpretada equivocamente e, dessa forma, acabar submetida a uma chave interpretativa redutora. Aliás, a própria denominação má-fé conduz facilmente a uma interpretação de cunho moralista, visto que pode soar como uma adjetivação que remete a algo ruim, disfuncional. Por conseguinte, tal olhar pode transformar a compreensão deste fenômeno em um rígido campo de julgamento entre escolhas certas e erradas. Contudo, há, de fato, uma moral em Sartre. Porém, ela não se aproxima do que podemos considerar como uma moral dita tradicional, que articula em seu bojo valores como Bem e Mal. Só pode existir uma moral em Sartre se a situarmos como uma moral que se estabelece na e pela liberdade e, neste contexto, Bem e Mal não podem ser tomados como valores objetivos dados a priori e sequer podem ser pensados apartados da atividade inventiva de uma liberdade que cria valores e doa sentido ao mundo. Simone de Beauvoir (2005) afirma que é próprio de toda moral tradicional "considerar a vida humana como uma partida que se pode ganhar ou perder, e ensinar ao homem o meio de ganhar" (p. 25). A principal diferença entre os princípios estruturantes da Moral - tradicional e sartreana - se dá, justamente, no ponto de partida: a concepção de homem. Como resume muito bem Beauvoir:

Não se propõe moral a um Deus; é impossível propôla a um homem se o definirmos como natureza, como dado; as morais ditas psicológicas ou empíricas não logram constituir-se a não ser introduzindo subrepticiamente alguma falha no seio do homemcoisa que elas primeiramente definiram (Beauvoir, 2005, p. 16).

Partindo, então, da concepção de homem pelo viés sartriano nos deparamos com uma realidade humana que é liberdade, que se define por sua perpétua incompletude.
O homem que nunca está pronto pode somente "brincar de ser" toda vez que esboça definir para si uma identidade fechada. Do mesmo modo que a moral só faz sentido a uma realidade humana inacabada também a má-fé só é possível ao ser que nunca é capaz de coincidir totalmente consigo mesmo: "se eu fosse triste ou covarde assim como o tinteiro é tinteiro, sequer seria concebível a possibilidade de má-fé” (Sartre, 2001, p. 113). Assim, a má-fé não se trata de um modo de ser "errado" ou uma escolha falsa, e sim de uma possibilidade sempre em aberto e volta e meia realizada pelo homem, isto é, atalhos inevitáveis em seu percurso existencial.

Aliás, toda interpretação do fenômeno da má-fé arrisca incorrer num equívoco se não for feita a partir de uma perspectiva ontológica, que é a que Sartre desenvolve em $O$ ser e o nada, e se, pelo contrário, se fixar, desde logo, num plano moral, de considerações normativas, sobre o que se deve e o que não se deve fazer (Anderson, 1993). De outro modo, seriam, por exemplo, ininteligíveis os momentos em que Sartre considera até a sinceridade como uma forma de má-fé. Por outro lado, importa distinguir dois âmbitos: um, persistente, em que podemos falar de uma escolha original de má-fé, e que assim estruturará todo o projeto de ser como projeto de má-fé; outro, transitório, em que ambas, a má-fé e a boa-fé são proporcionadas pela própria disposição meta-estável da consciência, podendo uma converter-se facilmente na outra consoante a conveniência das escolhas projetadas (Catalano, 1985). Na verdade, neste sentido transitório, a má-fé pode bem ser indispensável para que uma consciência se determine inteiramente a ser as escolhas que faz, vencendo o impasse da angústia (Barata, 2005). Em suma, o sentido profundo da má-fé se traduz brilhantemente nas palavras de Gerd Bornheim (2007): “a realidade humana nunca está realmente em casa, e quando pensa que está, incide em má-fé. O homem se habita perpetuamente como um estranho" (p. 126).

Pretendemos ter explorado aqui, justamente, algumas dificuldades e constantes fontes de mal-entendidos que, por vezes, acabam nos levando a leituras normatizantes, distorcendo, assim, os significados de noções caras ao pensamento sartriano. Como vimos, essas confusões se dão, principalmente, quando ocorre uma simples "importação" de conceitos da filosofia à psicologia, retirando dos mesmos sua riqueza de origem. Contudo, esses impasses não representam um impedimento ao diálogo interdisciplinar entre tais áreas, mas apenas dificuldades a serem trabalhadas que indicam, muito pelo contrário, possibilidades necessárias para quem deseja compreender o homem fora dos determinismos e dos reducionismos herdados pela psicologia desde o seu nascimento no auge do positivismo. Além do mais, percebemos que um olhar atento a esses temas aponta para um necessário delineamento da relação da psicologia fenomenológica de Sartre com a questão da ciência e do humanismo. Este mesmo olhar atento é que nos guia, portanto, a pensar 
as dificuldades, desafios e possibilidades de uma clínica com inspiração sartreana.

Resulta de todas essas considerações, que o ponto de partida adotado pelo psicólogo revela-se essencial para definir de que forma as relações podem ser articuladas no espaço clínico. Partindo da ontologia proposta por Sartre e de seu projeto de psicanálise existencial não podemos ansiar "corrigir" o homem em suas escolhas em busca de um processo terapêutico que potencialize uma atitude mais "livre" e saudável. Quando buscamos pensar a prática clínica a partir de Sartre devemos compreender, a princípio, que para o homem que está em vias de se fazer, que escapa a toda e qualquer lei de causalidade e determinismo, não existem explicações e caminhos prévios a serem alcançados. Longe de uma visão de natureza humana, de uma liberdade voluntarista e de uma má-fé sentenciadora,o que existe são possibilidades de ser que podem ser mais bem conhecidas e que, assim, colaboram para revelar esta perpétua escolha que o homem tem que fazer de si. Também, a fenomenologia nos mostra que a atitude de mover-se em direção a algo é constitutiva do próprio fenômeno. Portanto, compreendemos que sem este movimento de dar "um passo atrás”, convite da fenomenologia à psicologia, esta última corre o risco de produzir relações que, ao invés de abrir um campo de possibilidades de ser para aqueles que estão "em questão" na relação clínica, acaba por enclausurá-los em suas próprias verdades inquestionáveis. Desta forma, os contornos que circunscrevem uma relação clínica com base sartreana estão ainda por serem definidos, mas precisamos, antes de tudo, libertar essa relação das tendências aprisionadoras, que reduzem nossa visão de homem a simples esquemas teóricos. Por fim, seguindo uma inspiração sartrean, propomos que o objetivo de tal psicologia clínica deve ser entendido como aquilo que possa tornar a vida humana, de alguma forma, mais possível.

\section{Referências}

Alves, P. (1994). Irrefletido e reflexão: observações sobre uma tese de Sartre. Em Jean-Paul Sartre, A transcendência do Ego: esboço de uma descrição fenomenológica [p. 9-41]. Lisboa: Colibri.

Anderson, T.C. (1993). Sartre's Two Ethics - From Authenticity to Integral Humanity. Chicago: Open Court.

Barata, A. (2005) Liberdade e má-fé: avaliação de dois conceitos da filosofia de Sartre. Em P.Alves, J.M.Santos \& A.Franco de Sá (Eds.). Humano e Inumano - A dignidade do Homem e Novos Desafios [p. 395-404]. Lisboa: Phainomenon/Estudos de Fenomenologia.
Beauvoir, S. de (2005). Por uma moral da ambigüidade. Rio de Janeiro: Nova Fronteira.

Bornheim, G. (2007). Sartre: metafísica e existencialismo. São Paulo: Perspectiva.

Catalano, J. (1985). A commentary on Jean-Paul Sartre's Being and Nothingness. Chicago: Midway Reprint.

Feijoo, A.M.L.C. (2009) Clínica psicológica: filosofia e praxis. Em A.M.L.C.Feijoo (Org.). Psicologia clínica e filosofia [p. 41-72]. Belo Horizonte: Fundação Guimarães Rosa.

Gonçalves, C. (2006). Sartre e a psicanálise contemporânea. Dois Pontos (UFPR/UFSCar), 3 (2), p. 53-67.

Moreira, V. (2009). Clínica Humanista-Fenomenológica Estudos em psicoterapia e psicopatologia clínica. São Paulo: Anna Blume.

Sartre, J-P. (1987). O Existencialismo é um humanismo. Nova Cultura: São Paulo.

Sartre, J-P. (1994) A transcendência do Ego: esboço de uma descrição fenomenológica. Lisboa: Colibri.

Sartre, J-P. (2001). O Ser e o Nada: ensaio de ontologia fenomenológica. Petrópolis: Vozes.

Sartre, J-P. (2007). Esboço para uma teoria das emoções. Porto Alegre: L\&PM.

Fernanda Alt - Psicóloga clínica, Mestre em Psicologia Social pela UERJ, e graduada em Psicologia pela PUC-Rio. Foi professora substituta da UFRJ e atualmente dá aulas sobre existencialismo na Especialização em Psicologia Clínica do IFEN e em outros cursos de especialização. Endereço Institucional: Rua Barão de Pirassununga, 62 - Tijuca, Rio de Janeiro - RJ. E-mail: fernandaalt@gmail.com

Carolina Mendes Campos - Psicóloga clínica, Doutoranda em Psicologia da Puc-Rio, Mestre em Psicologia também pela PUC-Rio e Professora da Especialização em Psicologia Clínica do Instituto de Psicologia Fenomenológico-Existencial do Rio de Janeiro (IFEN). Endereço Institucional: Rua Barão de Pirassununga, 62 - Tijuca, Rio de Janeiro - RJ. E-mail: carolinamendescampos@gmail.com

André Barata - Professor da Universidade da Beira Interior (UBI) em Portugal, além de filósofo com doutoramento em filosofia contemporânea pela Universidade de Lisboa. Foi professor visitante do Instituto de Psicologia da UERJ. É autor de livros e artigos sobre filosofia e fenomenologia. Seus últimos títulos são "Mente e consciência - ensaios de filosofia da mente e fenomenologia" (2009) e "Sentidos de liberdade" (2007). Endereço Institucional: Universidade da Beira Interior, Faculdade de Artes e Letras, Rua Marquês d'Ávila e Bolama, 6200-001 Covilhã, Portugal. E-mail: abarata@ubi.pt

Recebido em 04.02.11 Primeira Decisão Editorial em 06.08.11 Aceito em 03.10.11 